\title{
Private label competition: the perspective of Swedish branded goods manufacturers
}

Magnus Hultman

Industrial Marketing and e-Commerce Research Group, Division of Business Administration \& Management, Lulea University of Technology, Luleà, Sweden

Robert A. Opoku

Department of Management and Marketing, King Fahid University of

Petroleum \& Minerals, Dhahran, Saudi Arabia, and

Esmail Salehi-Sangari, Pejvak Oghazi and

Quang Thong Bui

Industrial Marketing and e-Commerce Research Group, Division of

Business Administration \& Management, Lulea University of Technology, Lulea, Sweden

\begin{abstract}
Purpose - This paper aims to gain a better understanding of how Swedish branded goods manufacturers (BGMs) deal with the increased usage of private labels.

Design/methodology/approach - The approach takes the form of answering the three research questions of this study: how private labels are viewed by BGMs on the Swedish market; how Swedish BGMs strategically respond to the increases in private labels; and how the benefits and drawbacks of these strategic responses are perceived by Swedish BGMs. A contrasting multiple case study of four Swedish companies in the fast-moving consumer goods (FMCG) industry was used.

Findings - The perceived advantages of private labels are connected to their overall control of the market in which they operate, whereas the advantages of BGMs are seen to be linked to product development and superior brand reputation. BGMs respond to private labels by taking them seriously and striving to increase the perceived distance of their brands from private labels in the eyes of the consumers. The overall benefit of these strategies is perceived to be preparedness for increased private label competition, while the drawbacks vary between companies.

Research limitations/implications - In addition to empirical testing based on previous research on private label competition in a new setting, the study also presents suggestions for future research and the implications of the findings for managers.

Practical implications - Findings indicate that BGMs should take the emergence of private labels seriously, while at the same time striving to maintain good business relationships with the retailers. Originality/value - The study provides insights into the competitive situation between private labels and the manufacturer brands in the Swedish FMCG market.

Keywords Sweden, Labelling, Brand management, Competitive strategy, Retailing, Fast moving consumer goods
\end{abstract}

Paper type Research paper

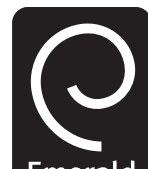

\section{Introduction}

In the current era, building strong brands has become a marketing priority for many organizations. The assumption here is that by building a strong brand, a number of marketing advantages will accrue. In consumer marketing, for instance, brands often provide the primary points of differentiation between competitors' offerings, create brand identification and awareness, guarantee a certain level of quality and 
MRN

31,2

126 satisfaction and facilitate the promotional activities related to a product or service (Hollensen, 2003). As such, brands are today recognized to be a cornerstone of most marketing plans and strategies.

When considering present-day brands, the type of brands classified as being manufacturer brands would most likely come to mind. Lists of all the leading brands today, from Coca-Cola to the likes of Disney and Marlboro, all fall under the umbrella of a manufacturer's brand (Keller, 2003). A distinctive hallmark of brands of this type is that they are created by producers and thus bear their own specifically chosen brand name. Consequently, the value of the brand is retained in the hands of the producers. De Chernatony and McWilliam (1988, p. 4) define a manufacturer brand as "an added value entity conceived and primarily developed by a manufacturer for a specific group of customers and consumers, which portrays a unique relevant and distinctive personality through the support of product development, promotional activity and an appropriate pricing and distribution strategy". This type of brand goes under many names including national brands or branded goods. However, throughout this study, the terms "manufacturer brands" or "national brands" are used when referring to these brand types. The producers of these are referred to as branded goods manufacturers (BGMs).

For a substantial period, the retailing industry has provided its customers with goods branded by manufacturers. Nevertheless, manufacturers soon realized the potential benefits of producing and carrying brands of their own - private labels. These labels are nowadays in many ways considered to be comparable to national manufacturer brands and consequently, the BGMs have begun to take appropriate competitive actions (Parker and Kim, 1995). Kotler (1997, p. 447) has even gone so far to call this development a "battle between manufacturers' brands and store brands". According to Håkansson (2000), there is an overabundance of different names and definitions used to describe the concept of retailer-owned brands. While some authors use the term "private labels", others prefer words like "own brands", "retailer brands", "wholesaler brands" or "distributor own brands". Throughout this paper, the term "private labels" is used to describe retailer-owned brands. According to Baltas (1997, p. 315), such brands can be defined as "consumer products produced by, or on behalf of, retailers and sold under the retailers' own name or trade mark through their own outlets".

The developments of private label brands (Laaksonen and Reynolds, 1994), their powerful nature and competitive edge (Davis, 1994; Laaksonen and Reynolds, 1994), their importance (Dunne and Narasimhan, 1999; Hoch and Banerji, 1993) and their role as a source of major concern among consumer goods manufacturers (Ashley, 1998) have been discussed widely since the early 1990s. Montezemolo (1997) suggests that the growth of private labels is transforming the role of the distributor from friendly client to a fierce competitor - and a competitor with a trump card, since this competitor knows about the marketing plans, new product advantages and the promotional efforts of the manufacturers in a competitive market. Although many substantial academic studies have been undertaken within the broad field of branding research, researchers nevertheless agree that additional efforts are required in the area of manufacturer brands and the relationship between this brand type and private labels (cf. Parker and Kim, 1995). Therefore, it is worthwhile to further investigate the options available to BGMs to determine their responses to the intrusion of private label brands into a competitive market. 
Researchers like Baltas (1997) and Miller (1995) found the ways in which BGMs actually view the increased use of private labels, a particularly interesting area to study. According to Parker and Kim (1995), to their knowledge, no marketing study has considered sufficiently the potential competition/collusion relationship between the established manufacturer brands and the private label brands. In the light of this opinion, our study seeks to discover what BGMs today think about private labels. Furthermore, BGMs across Europe appear to have a good reason to be concerned about the private label phenomenon (Montezemolo, 1997). For instance, according to Anselmsson et al. (2005), Sweden is the market where private label products achieved the highest growth rate in the Western hemisphere - these products increased by 275 per cent in the past four years. In fact, fighting private labels has been a major concern in Sweden (Hofmann, 2006; Steenkamp et al., 2005). Yet, to our knowledge, very few similar studies have emerged in this field. Therefore, an examination of the field from a Swedish perspective is both highly relevant and timely. With this in mind, the study seeks to gain better understandings about how Swedish BGMs counter the increased use of private labels. Considering the research streams identified by previous researchers as being important, the three research questions below guide our study:

(1) How do Swedish BGMs perceive private label activity?

(2) How do Swedish BGMs respond to private labels in terms of strategies they adopt?

(3) How do Swedish BGMs perceive the benefits and drawbacks of the strategies they adopt in response to private labels?

The remainder of the paper presents a cursory overview of previous studies relevant to our area of investigation and describes our choice of methodology. Following this, we present the findings and discuss their implications. Finally, we identify the study's limitations and offer directions for further research.

\section{Literature review}

Diverse arguments have been mounted to distinguish national brands from private labels and reveal the relative advantages of each branding strategy. Hoch (1996), for example, argues for a clear distinction between private labels and national brands. Quelch and Harding (1996) also list several factors, which would suggest that private labels currently possess advantages over manufacturer brands. Others have in their turn, argued in favor of national brands. For instance, Taylor and Rao (1982) suggest that consumers experience greater confidence when purchasing well-known brands in less-known stores than they do when purchasing less-known brands in well-known stores. Rao and Monroe (1989) support this assertion in a later study and found a positive relationship between price and perceived quality, and between brand name and perceived quality whilst the relationship between a store's name and perceived quality was statistically insignificant. Hoch (1996) also recognizes two major advantages that manufacturer brands have over private labels based on his research. First, private labels seem to be more sensitive to price changes compared to manufacturer brands. Hence, a private label would lose more customers if its price were raised compared to the loss a manufacturer brand would suffer under similar circumstances. Second, manufacturer brands are generally perceived to deliver higher levels of product quality and consistency.
Private label competition 
MRN

31,2

128

The issue of BGMs producing private labels has received special interest among the research community. Several researchers list the advantages and disadvantages that follow from a private label-production strategy. The main advantages are that excess manufacturing capacity is utilized (cf. Glemet and Mira, 1993; Halstead and Ward, 1995; Hoch, 1996; Quelch and Harding, 1996), the manufacturer-distributor relationship is strengthened (Hoch, 1996) and competition by private label brands is reduced since it indirectly assists in keeping the prices of manufacturer brands at a low level (Halstead and Ward, 1995). In addition, by producing private labels, production experience is increased and both the unit manufacturing and distribution costs are lowered. A private label-production strategy also helps BGMs smooth out production peaks and finally, private labels also take less time and effort per unit to sell compared to the company's own manufacturer brands (Quelch and Harding, 1996).

The main disadvantages of a production strategy emerge as the risk of cannibalization as BGMs are indirectly helping their competitors undermine their own brands (cf. De Chernatony and McDonald, 1998; Halstead and Ward, 1995; Hoch, 1996; Quelch and Harding, 1996). There is also the risk of the original strategy becoming confused. So too, a BGM might run into additional manufacturing and distribution complexities, which add to costs rather than reducing them. Another disadvantage is that BGMs must maintain two sales relationships with each retailer instead of one (Quelch and Harding, 1996).

Two researchers unsympathetic towards the option of producing private labels are Quelch and Harding (1996). Instead of proposing production, they offer ten measures available to BGMs to halt the gains made by the private labels. The authors stress that these strategies are applicable even when BGMs make private label products. The strategic options include:

(1) Investing in brand equities.

(2) Innovating wisely.

(3) Using fighting brands sparingly.

(4) Building trade relationships.

(5) Managing the price spread.

(6) Knowing the price elasticity.

(7) Exploiting sales promotion tactics.

(8) Managing each category.

(9) Using category profit tools as a performance measure.

(10) Taking private labels very seriously.

A segment of research has also examined how the BGMs react towards increased private label competition (see Garretson et al., 2002; Halstead and Ward, 1995; Hoch, 1996; Quelch and Harding, 1996). Hoch (1996) argues for the delicate nature of this issue because the BGMs time must think and act differently towards private labels than towards other manufacturer brands due to the fact that the producers of the private label brands might be customers and competitors at the same time. Ailawadi and Keller (2004) call for research that is more empirical to determine the effectiveness of the responses of manufacturers. Hoch (1996) elaborates on this issue with six strategic measures available for a BGM to improve its competitive position towards private labels. The options listed are meant to be neither mutually exclusive nor 
exhaustive. Furthermore, the viability of each measure is likely to depend on the distance between the private label and the brand of a BGM, both on quality and price dimensions. Hoch's measures are:

(1) Wait and do nothing.

(2) Increase distance from private labels.

(3) Reduce the price gap.

(4) Formulate a "me too" strategy.

(5) Make regular or premium private labels.

(6) Cooperate with private labels directly to the retailer.

Hoch concludes the advice concerning preferred strategic options by stating that no single option is superior and under the appropriate circumstances, virtually any strategy will work.

\section{Methodology}

In order to compare the two branding approaches and gain enough informed understandings of the private label phenomena to be able to answer this study's research questions, we chose an in-depth multiple case study methodology. Yin (1994, p. 45) agrees with choices of this type, suggesting that "the evidence from multiple cases is often considered more compelling, and the overall study is therefore regarded as being more robust”. To achieve a higher level of validity and allow for triangulation (cf. Yin, 1994), documentation, observations and interviews were all used in this study. Documentation refers to material that we collected in the form of brochures, annual reports and other related sources provided by the respondents or accessed via the companies' websites. Observations were undertaken of the companies' marketing mixes inside and outside of the stores, and interviews were conducted with respondents from four companies competing in the Swedish fast moving consumer goods (FMCG) industry.

To exploit the benefits of contrasting cases (Miles and Huberman, 1994), companies focusing on different product categories were selected. In this case, companies active within the chemical consumer product and consumer food product segments were chosen. This selection is justified on the grounds that previous research proposes that these two categories differ considerably in terms of how many private labels have interfered with the market (Kapferer, 2001). The sampling frame was set to large international corporations with strong brands vending FMCG through retail outlets in the Swedish market. These types of companies in the FMCG industry appeared to be the ones most severely affected by the recent growth of private labels (Kapferer, 2001). Therefore, senior managers within these companies should know the most about the subject in question.

Concerning the number of cases in a multiple-case study, Miles and Huberman (1994) declare that the number of cases depends on the richness and complexity of the within-case sampling. Since the research questions of this study provide a quite high degree of complexity for each case, four cases were selected. Two cases are represented in each of the aforementioned product categories.

A profile of each of the companies chosen as the sample for this study is set out in Table I. Due to the confidential nature of the data, at the request of the participants, the
Private label competition 
MRN

31,2

A

130

$\mathrm{C}$

$\mathrm{D}$

Table I.

Profile of the four

Swedish companies

\section{Profile}

Company structure and market

Conducts marketing and sales of products. The bulk of the company's products are manufactured not only in its own Swedish factories but also in other

European locations. Some external distributors.

Products

Toiletries, health care, wound care, household and first aid.

Background, turnover and size

Originally a Swedish company, it was acquired by a large US corporation some time ago. Still characterized as a "stand alone" business - company is mostly self-sufficient in the European market, where it operates. Turnover just below 150 million US\$ in 2005; about 400 employees.

Participant type

Business Area Manager.

Company and market

A multi-billion dollar company serving people in $200+$ countries and territories. Products

Consumer products through strong global brands; mainly in the categories oral care, personal care, household surface care and fabric care.

Background, turnover and size

Has long history and considers itself truly global in scope. Production facilities and sales offices throughout the world. The Swedish subsidiary had a turnover of around 75 million US\$ in 2005; employs 50+ people.

Participant type

Customer Marketing Director responsible for all products in the Swedish market.

Company and market

Leading food stuffs provider in Sweden, conducting marketing and sales of products via retail outlets to consumers as well as directly to restaurants and caterers.

Products

Frozen food category with highly active colonial products segment.

Background, turnover and size

Production facilities in a variety of European locations and Asia. Sales are conducted in some 20 countries but focus is on Europe. Swedish subsidiary's turnover was $300+$ million US\$ in 2005 ; employs $1,000+$ people.

Participant type

Sales Director of the Swedish market.

Company and market

Very large global manufacturer of commodity goods. Leading suppliers of food products in Scandinavia in the FMCG sector through a variety of brands. The parent company is a global corporation with over 1,000 brands through 300 subsidiary companies in 100 countries. Employs 200,000+ people world-wide. Products

Primarily food stuffs, drinks, laundry detergents and hygiene products.

Background, turnover and size

The Swedish operations are organized around a number of subsidiaries, one of them dealing with food products. This subsidiary (Company D) employed 500+ people in 2005 and had a turnover of $300+$ million US\$.

Participant type

Customer Business Manager.

registered names of the companies were disguised. Considerable effort was expended in identifying representatives whose position would enable them to provide broad perceptions of their company's view of private labels as well as its strategic responses 
to them. To this end, we first scanned a number of private label-carrying supermarkets with an aim to locate national brands within the targeted segments. We aimed for national brands with varying degrees of market success in order to obtain some variability in the responses. When suitable brands had been located, the companies behind the brands were contacted via telephone in an attempt to identify key respondents and request for their participation in the current investigation. In order to ensure that they possessed the expertise necessary to act as key respondents in this study, the company representatives who agreed to participate were screened through a series of questions on their knowledge about their companies' private label-response strategies. This procedure eliminated two initial representatives and led to new referrals within their companies. Since the final list of respondents held senior management positions such as business area manager, customer marketing director, sales director and customer business manager, alongside with the fact that they all claimed to have the necessary experience and knowledge on their companies' strategies for the Swedish market, they were deemed to be respondents highly suited to providing meaningful data for our study. This utilization of one single key informant per investigated company is further motivated by the fact that our documentation and observations enabled us to double-check the information provided during the interviews.

At the respondents' convenience, in-depth interviews were thereafter conducted by a team of experienced researchers. The interviews were conducted via a conferencetelephone system in a very open-ended and conversational manner, however, some guidance was still provided through the use of a semi-structured interview guide available to both the interviewers and the respondents. The rationale here was to preserve interview flexibility, capture ad hoc perceptions and create opportunities to raise additional areas relevant to the subject matter without drifting too far away from the subject at hand. The interviews, which lasted about $2 \mathrm{~h}$ each, were recorded and full transcripts were produced within two days of the interviews. When judged by the researchers to be necessary, additional communication was undertaken with the managers by telephone or email.

The principal questions dealt with during the interviews were related directly to the three research questions set out above. In other words, we sought to discover how the Swedish BGMs generally perceived private labels, the types of strategies they adopted to defend the threat of private labels, and the benefits and drawbacks they identified relating to the strategies they adopted.

\section{Results and discussion}

The issue of how BGMs dealt with the increase in the use of private labels is addressed below. More specifically, the research questions of the study provide the basis for comparing the data derived from the cases with previous research findings. The variety of responses across the cases are highlighted and summarized following the order of the research questions.

Perception of private labels by BGMs

In an overall sense, the managers of all the companies in the study strongly concurred that private labels are "here to stay" and that their position in the Swedish marketplace is constantly growing stronger. At a more specific level based on the perceptions of the managers interviewed, Table II illustrates the advantages that private labels appear to have over the manufacturer brands and vice versa.

\section{Private label competition}


MRN

31,2

132

Perceived advantage

A

B

Case

Private labels

Superior coverage and penetration

Retailer control

$132 \quad$ Placement

Piggybacking

No 100 per cent trade deal pass through

Improved private label quality

Current European private label trend and success

Emergence of new channels

The creation of new categories

New product activity

Manufacturer brands

Simplifies consumers' selection process

Brand name reputation

Table II.

The brand has value to the retailer

Perception of private

Lower price elasticity

labels by BGMs

Superior quality and product development

Considering the advantages offered by private labels, it first becomes evident that the retailers' proposed full-control over their brands' advertising levels and overall image are both regarded as strong advantages by the managers in each of the four companies - a line of reasoning supported in Hoch's (1996) work. Moreover, the fact that retailers can make relative independent decisions about how they place and position their private labels in stores (Hoch, 1996) seems to be considered a strong advantage given that all the companies in the study recognized the importance of placement. Other advantages of private labels, which appear to be strong, include their superior coverage and penetration in stores (cf. Hoch, 1996), their current success among European supermarkets (cf. Quelch and Harding, 1996) and the upsurge in new channels and outlets carrying them (cf. Quelch and Harding, 1996).

Other advantages are somewhat unevenly spread; the claim that retailers do not always provide 100 per cent pass trough, meaning that they are not letting the end consumer benefit from the full rebate provided by the BGM during trade deals (Hoch, 1996; Quelch and Harding, 1996), was only recognized by the managers at the two chemical consumer product companies ( $\mathrm{A}$ and $\mathrm{B})$. The manager at company $\mathrm{C}$ explained that because his company is a market leader in many categories, the retailers have no choice other than to offer 100 per cent pass trough on deals in order to avoid losing those customers who want their products. On the other hand, the managers of the consumer food category companies (C and $\mathrm{D})$ viewed the improved quality of private labels (cf. Quelch and Harding, 1996) as a major threat whereas the other managers did not share this point of view. When commenting on this viewpoint, the manager at company A claimed that to improve quality, retailers must also increase their price, the consequence of which would be the loss of their main source of competitive advantage. On the same issue, company B explained that they were always one step ahead of private labels quality-wise because of the continued attention given to product development. Across the cases, the manager in company A identified the most number of advantages stemming from private labels while the respondent in 
company $\mathrm{C}$ identified the least. All of the advantages identified in the existing literature also seem to have been identified by at least one of the managers in each of the companies in our study.

A review of the advantages that the companies have over private labels reveals two fundamental advantages. First, all managers agreed that the reputation manufacturer brand names enjoy vis-à-vis private labels is perhaps the strongest advantage across the board. This advantage is in line with the reasoning of researchers such as Hoch (1996) and Quelch and Harding (1996). The second major advantage identified by all managers - quality and product development - might be the underlying factor behind the first advantage. As one manager explained, "without continued product development, our brands will not be able to maintain their superior quality, and if this happens, the reputation of the brands will slowly deteriorate". It is noteworthy that this obviously strong advantage was not mentioned by any of the previous researchers cited in the literature review.

Another important observation is that the brands of the chemical consumer companies appear to possess relatively more competitive advantages over private labels than the brands of the consumer food companies. This observation reinforces Kapferer's claim that chemical products receive less competition from private labels than food products do at the present time (Kapferer, 2001). With the exception of new category creation and new product activity, which were only identified by the respondent at company $\mathrm{A}$, managers in at least two of the investigated companies also identified all of the manufacturer brand and private label advantages identified in the literature. This is an indication that the propositions about private label advantages and disadvantages discussed in previous research are also applicable to the Swedish context.

\section{Strategies adopted by BGMs: perceived benefits and drawbacks}

Table III displays the strategies adopted by the companies investigated in this study as a way to come to terms with the advance of private labels. It also reveals the benefits and drawbacks that accompany the adopted strategies. An empty cell in the table indicates that the company in question is not pursuing the specific strategy. A company's benefits and drawbacks as the result of a pursued strategy is represented either as a positive (that is "+", which identifies a perceived benefit) or a negative (that is “-”, which indicates a perceived drawback). All the strategic actions pursued by the companies identified in this investigation were also identified in previous research (see, for example, Glemet and Mira, 1993; Halstead and Ward, 1995; Hoch, 1996; Miller, 1995; Montezemolo, 1997; Parker and Kim, 1995; Quelch and Harding, 1996).

Concerning the main strategies adopted by the companies studied, considerable differences are discerned not only between the companies but also between the two product categories. For instance, neither company A nor company B managers initially claimed to be adopting any specific strategies in response to the emergence of private label brands. The reason offered was that they apparently viewed private labels as merely a secondary type of competition. Therefore, managers saw no point in treating private labels any different to other competitive elements in the market.

In the case of both of the consumer food companies, managers explicitly conceded that they pursued strategies directed purposely towards countering the impact of private labels. Strategies of this type were mainly aimed at increasing the distance from private labels through continuously strengthening the brands in order to convince
Private label competition

133 
MRN

31,2

\section{4}

Table III.

Strategies adopted by BGMs and their perceived benefits/ drawbacks




customers that they offered a value-added option. The manager at company $\mathrm{C}$ too specifically acknowledged working with value flankers (without going into further details about this because of confidentiality reasons) while the manager at $\mathrm{D}$ indicated that they actively competed with private labels by managing their price structure through effective monitoring techniques and an efficient cost structure throughout their supply chain.

Despite this initially interesting distinction between the two categories, some further in-depth discussion and probing with the managers from the consumer chemical companies towards the end of the interviews revealed that these companies were actually indirectly designing strategies to compete with private labels in particular. Thus, it became evident that all companies were competing with private labels by working towards increasing the perceived distance between their brands and those of the retailers in the eyes of the consumers. The advantages that flowed from this strategy were that it provided customers with added value while simultaneously enhancing the consumers' perceptions about the superiority of a BGM's products. The principal drawback was that the strategy was purportedly limited to those products, which were slightly more expensive and diversified. Company $\mathrm{B}$ differed from this pattern in that its managers did not identify any apparent weaknesses and the belief that the perceived superiority of the brand seemed to be the sole obvious benefit.

All four companies appeared to assume a state of general preparedness for the future by pursuing a strategy of taking private labels seriously, as proposed by Quelch and Harding (1996). There was a very high level of consensus among all managers that private labels should be taken seriously and indeed, the four companies were engaged in this endeavor to various extents. The respondent at A claimed that the progress of private labels was closely monitored by their organization, while the B manager had started to consider more direct strategic actions in order to temper the coming challenge of the private labels. Furthermore, the $\mathrm{C}$ manager believed that a BGM, which fails to take private labels seriously, should not be considered as a serious BGM. As might be anticipated in the present climate, all managers recognized that the tactic of taking the private labels seriously enabled their companies to quickly implement appropriate strategic measures without first unnecessarily damaging the existing supplier-retailer relationship. Only the manager at $\mathrm{C}$ expressed the reservation that an excessive focus on private labels runs the risk of forsaking other equally important business activities. The results also indicate that none of the managers were suggesting that their companies should follow the passive "wait and do nothing" option. While their companies were not currently producing private labels for retailers, this option was not entirely discarded by the managers interviewed as an option for their companies in the future.

Only managers at $\mathrm{A}$ and $\mathrm{D}$ were working towards reducing the price gap, primarily by lobbying the retailers to raise the prices of their private labels. The respective benefits and drawbacks identified by the managers of both companies were the chance of gaining market share at the expense of lower profit margins. One possible consequence of this action might be the other observed similarity between A and D; namely, both were actively managing their prices in response to the private label competition in the hope of being able to react swiftly to future price changes by private label competitors.

Managers at $\mathrm{B}$ and $\mathrm{C}$ also managed prices actively but not specifically in response to private labels. The same applies to all companies when it comes to the use of
Private label competition

135 
MRN

31,2

136 advertising and sales promotion. The final difference between the companies was that $\mathrm{B}$ alone was striving towards building stronger trade relations with its retailers in order to minimize the impact of private labels on their business. The B manager proposed that many advantages could be derived from this strategy. The advantages identified were win-win situations, favored trade accounts and opportunities to prevent shelf space occupation by private labels and hence, better exposure of the company's own brands. The other three companies were not working on their trade relations, with private labels specifically in mind. Therefore, managers here could not identify specific benefits or drawbacks in this context.

To summarize the above discussion, despite all of the observed differences, there are also common denominators among the four companies investigated in this study. All are extremely serious about how they approach private label competition and all appear to be actively working towards increasing their perceived distance from private labels by continuously developing their products and working on activities that improve their brand equity.

\section{Conclusions}

The purpose of this study was to gain an informed understanding concerning how BGM view the increased use of private labels. This quest was supported by three research questions, which sought to discover how Swedish BGMs perceive private label activity, how they respond to private labels in terms of the strategies they adopt and how they perceive the benefits and drawbacks of the strategies they adopt in response to private labels.

\section{How do BGMs perceive private label activity?}

Our findings suggest that private labels are growing and will most likely continue to do so until a substantial share of the Swedish market has been captured. The advantages that private labels possess over manufacturer brands are strongly connected to the fact that the private label concept enables retailers to control both the product as well as the market. The BGMs view their main advantages to be their capability to develop original products and categories that delivers added value and favorable reputations among consumers.

Consequently, retailers are perceived to enjoy a strong competitive advantage given that they can decide on and control the placement and amount of private labels offered in their stores, without having to deal with entry barriers and other complicating factors associated with reaching consumers. On the other hand, BGMs see that their most vital advantages towards private labels are rooted in their superior R\&D capabilities as well as the solid reputation and positive associations derived from their brands. It became clear that the majority of companies in this study viewed brand name reputation, product development and to some extent, the simplification of the consumers' selection process as very important advantages for manufacturer brands. Based on this fact, it can be concluded that the fundamental benefits traditionally sought after in any strong and solid brand regardless of industry are also the advantages perceived to be most useful when competing against private labels in particular.

The companies studied did not identify a private label advantage in the development of premium private label brands. Since the managers saw private labels as being far from fully developed in Sweden, it can be concluded that the present threat 
to manufacturer brands is yet to reach its full potential. Nevertheless, the importance of private labels is predicted to grow significantly in the Swedish market in the foreseeable future. One advantage of private labels that was acknowledged by a majority of company managers was the success of European supermarkets with private labels (particularly in UK). This can serve as a source of motivation for Swedish retailers, which also would provide encouragement for them to further develop and strengthen their private labels. In this light, we conclude that although somewhat a minor today, the development of premium private label brands will be an advantage in the coming decade.

Taken together, the main advantage that private labels possess over manufacturer brands is that private brand producers have simultaneous control over their products and markets. The main advantages that manufacturer brands possess over private labels are the strength of the brand, access to $\mathrm{R} \& \mathrm{D}$, the capacity for product development and the value of the brand among consumers.

How do BGMs respond to private labels in terms of strategies they adopt?

The findings indicate that BGMs respond to private labels by first taking them seriously and then making the appropriate arrangements to counter the expected future increase in the level of competition. This implies that BGMs are definitely not just sitting around waiting while the private labels are allowed to flourish unhindered. Although managers of the Swedish BGMs in the chemical consumer product category initially claimed they were not using any direct strategies purposely aimed towards private labels, it was deduced that all the companies in one way or another, took measures to increase their distance from the private labels in the eyes of the consumers. The fact that the managers of companies within the chemical consumer product category did not specifically admit to pursuing any direct response strategies towards private labels - while those in the consumer food companies did - indicates that there is a notable difference concerning private label penetration between product categories on the Swedish market. For instance, the results of the current study would suggest that private label activities within chemical consumer products are presently not considered as a significant competitive threat whereas private labels in the consumer food category are perceived to be more successful at narrowing the gap between the private labels and manufacturer brands.

Still, the analysis eventually revealed a strong need among all the companies to treat competition from private label as a deadly seriously business. In this context, managers are taking strategic measures. This commitment indicates that private labels are no longer treated as a second-rate competitor in the Swedish FMCG market. As asserted by one manager, "anyone not considering private labels a serious actor cannot be seen as a serious brand".

The explanation of why the companies, directly or indirectly, strive to increase their distance from private labels could be that the measures mentioned are core business activities. Building, maintaining and strengthening brands has always been considered as a way of survival for companies of the type investigated. These processes are at the heart of facing competition (Davis, 1994). However, this traditional approach has gained new meaning with the emergence of private labels. In the light of the conclusions about the main advantages of private labels, BGMs must strive harder than ever before to reach a favorable association with their brands as they now have to compete with the retailers' own brands as well.
Private label competition 
MRN

31,2

138
None of the BGMs in the study currently produced private labels. However, it was gleaned that these companies were deliberating on the option and may consider producing private labels in the future. This proposition is reinforced in the statement of one manager who said that "today, the main attitude among manufacturers towards (private labels) has shifted from a clear and concise "no", to something that is taken under a good deal of consideration - or even implemented". Since BGMs today, to a greater extent, view private labels as a desirable and viable option, it could be a further indication that private labels have become a considerable force to be reckoned with in the Swedish market. In short, the strategic responses of the BGMs can be summarized in three points:

(1) Private labels are taken very seriously.

(2) There is a strive towards increasing the distance from private labels.

(3) Some seriously consider producing private labels.

How do branded goods manufacturers perceive the benefits and drawbacks of the strategies they adopt in response to private labels?

Based on the findings of this study, BGMs see that the main benefit of their adopted strategies is to be prepared for increased competition from private labels. All the Swedish BGMs studied fear that adopting a "wait and see" strategy is unsustainable. The adopted strategy of taking private labels seriously enables them to expediently instigate strategic measures when required. Furthermore, striving towards increasing the distance from private labels is seen by a majority of BGMs to provide added value to their brands while simultaneously enhancing their perceived superiority. The benefits and drawbacks of the remaining adopted strategies differ considerably between BGMs.

The managers of companies adopting a strategy to increase their distance from private labels, see benefits such as adding value to the customers, which enhances the brand's superiority in the eyes of the consumers. From these results, it is concluded that the perceived benefits of the BGMs' chosen strategy are closely tied to the previously stated advantages that they claimed to hold over private labels in the first place, mainly product development and brand name reputation. In other words, the strategic measure of increasing distance from private labels is used in order to further strengthen the already perceived advantages that manufacturer brands allegedly hold over private labels. Thus, the desire of BGMs to excel at their core business motivates them to offer brands that provide significant value to their customers. The main conclusions derived from this study concerning how BGMs perceive the benefits and drawbacks of the strategies they adopt in response to private labels are briefly summarized below:

- The strategies prepare them for increased competition from private labels.

- The strategies provide opportunities to take future strategic measures.

- The drawbacks vary between BGMs.

To conclude, it has become clear that BGMs view private label activity seriously and the choice of strategies adopted to combat this threat as critical. 
Implications and future research directions

Implications for management

The study indicates that private labels are a growing force in the Swedish market. Based on the literature and the information gained from interviews with managers across the four cases, we recommend that managers generally in this new and dynamic environment take the emergence of private labels seriously - it is not transitory trend that will soon blow over. Instead, approaching private labels in a professional manner should be the foundation stone upon which the strategies developed to counter private label competition rests. Nevertheless, the results also indicate that it is fundamental for both BGMs and retailers to continuously seek out favorable trade relationships and not overreact to private labels with extreme offensive or defensive strategies, which could serve to harm long-standing and hard-won business relationships. Just because an increasing number of retailers are initiating private label programs, this does not imply that manufacturer brands are "out for the count". On the contrary, the two are still very much dependent on one another in the market. Therefore, it is important for managers of BGMs not only to maintain the existing relationships but also to seek out and create new forms of collaborations with the retailers.

\section{Recommendations for further research}

This study utilized only a small sample of Swedish companies representing the FMCG industry (specifically, the chemical consumer and the consumer food product categories). Consequently, the findings and conclusions cannot be considered as widely applicable outside these specific settings. Nevertheless, we suggest that the findings might serve as a base for the construction of hypotheses, which in a later study could be tested quantitatively in other settings.

The two product categories investigated in this study could be classified as relatively high-involvement ones in the eyes of consumers. This could explain why the BGMs studied have not yet committed to a production-based response to private labels. Thus, it would be interesting to study companies in the low-involvement categories or commodity type products, as these companies might be found to pursue different methods when faced with competition from private labels.

\section{References}

Ailawadi, K.L. and Keller, K.L. (2004), "Understanding retail branding: conceptual insights and research priorities", Journal of Retailing, Vol. 80 No. 4, pp. 331-42.

Anselmsson, J., Johansson, U., Maranõn, A., Persson, N. and Ulver, S. (2005), Retailer Brands and Effects on Swedish Consumer Prices, 2005/1, Lund International Food Studies, Lund.

Ashley, S.R. (1998), "How to effectively compete against private-label brands", Journal of Advertising Research, Vol. 38 No. 1, pp. 75-82.

Baltas, G.A. (1997), "Determinants of store brand choice: a behavioral analysis", Journal of Product \& Brand Management, Vol. 6 No. 5, pp. 315-24.

Davis, S.M. (1994), “Commentary: securing the future of your brand”, Journal of Product \& Brand Management, Vol. 3 No. 2, pp. 42-9.

De Chernatony, L. and McDonald, M.H.B. (1998), Creating Powerful Brands in Consumer, Service and Industrial Markets, 2nd ed., Butterworth-Heinemann Ltd, Oxford.

De Chernatony, L. and McWilliam, G. (1988), "Clarifying the difference between manufacturers' brands and distributors' brands”, Quarterly Review of Marketing, Summer, pp. 1-5.
Private label competition

139 
MRN

31,2

140

Dunne, D. and Narasimhan, C. (1999), "The new appeal of private labels", Harvard Business Review, Vol. 77 No. 3, pp. 41-9.

Garretson, J.A., Fisher, D. and Burton, S. (2002), "Antecedents of private label attitude and national brand promotion attitude: similarities and differences", Journal of Retailing, Vol. 28 No. 2, pp. $91-9$.

Glemet, F. and Mira, R. (1993), "The brand leader's dilemma”, The McKinsey Quarterly, Vol. 33 No. 2, pp. 3-15.

Håkansson, P. (2000), "Beyond private label - the strategic view on distributor own brands", doctoral dissertation, EFI Stockholm School of Economics, Stockholm.

Halstead, D. and Ward, C.B. (1995), "Assessing the vulnerability of private label brands", Journal of Product \& Brand Management, Vol. 4 No. 3, pp. 38-48.

Hoch, S.J. (1996), "How should national brands think about private labels?", Sloan Management Review, Vol. 37 No. 2, pp. 89-102.

Hoch, S.J. and Banerji, S. (1993), "When do private labels succeed?", Sloan Management Review, Vol. 34 No. 4, pp. 57-67.

Hofmann, O. (2006), "Private label products boom in Swedish household care", available at: www.euromonitor.com/Private_label_products_boom_in_Swedish_household_care (accessed 11 October 2006).

Hollensen, S. (2003), Marketing Management - A Relationship Approach, 1st ed., Pearson Education Ltd, London.

Kapferer, J.-N. (2001), [Re] inventing the Brand - Can Top Brands Survive the New Market Realities?, Kogan Page, London.

Keller, K.L. (2003), Strategic Brand Management: Building, Measuring, and Managing Brand Equity, 2nd ed., Prentice-Hall, Upper Saddle River, NJ.

Kotler, P. (1997), Marketing Management: Analysis, Planning, Implementation and Control, Prentice-Hall, Upper Saddle River, NJ.

Laaksonen, H. and Reynolds, J. (1994), "Own brands in food retailing across Europe”, Journal of Brand Management, Vol. 2 No. 1, pp. 37-46.

Miles, M. and Huberman, M.A. (1994), Qualitative Data Analysis: An Expanded Source Book, 2nd ed., Sage, Thousand Oaks, CA.

Miller, C. (1995), “Big brands fight back against private labels”, Marketing News, Vol. 29 No. 2, pp. 1-8.

Montezemolo, G. (1997), "When client turns competitor: how to deal with growing competition from retailers' own labels”, Business Europe, January, pp. 9-10.

Parker, P.M. and Kim, N. (1995), National Brands versus Private Labels: An Empirical Study of Competition, Advertising and Collusion, INSEAD-95-32-MKT, Institut Européen d'Administration des Affaires, Fontainebleau.

Quelch, J.A. and Harding, D. (1996), "Brands versus private labels: fighting to win", Harvard Business Review, Vol. 74 No. 1, pp. 99-110.

Rao, A.R. and Monroe, K.B. (1989), "The effect of price, brand name, and store name on buyers' perceptions of product quality: an integrative review", Journal of Marketing Research, Vol. 26 No. 3, pp. 351-7.

Steenkamp, J.-B.E.M., Geyskens, I., Koll, O., Gielens, K. and Lewis, H. (2005), Fighting Private Labels in Sweden: Growth Drivers, Brand Defense Strategies and Market Opportunities, Business Insights Ltd, London.

Taylor, R.L. and Rao, C.P. (1982), "An assessment of the interaction effects of brand and store reputation on consumer perceived risk and confidence", Akron Business and Economic Review, Vol. 13 No. 2, pp. 43-7.

Yin, R.K. (1994), Case Study Research: Design and Methods, 2nd ed., Sage, Thousand Oaks, CA. 


\section{About the authors}

Magnus Hultman is a Lecturer and a $\mathrm{PhD}$ candidate in the Industrial Marketing, Industrial Marketing and e-Commerce Research Group at the Luleå University of Technology in Sweden. Magnus Hultman is the corresponding author and can be contacted at: magnus.hultman@1tu.se

Robert A. Opoku is a Lecturer in Management and Marketing at the King Fahid University of Petroleum \& Minerals in Saudi Arabia.

Esmail Salehi-Sangari is the Professor and Chair of the Industrial Marketing and e-Commerce Research Group at Luleå University of Technology in Sweden.

Pejvak Oghazi is a $\mathrm{PhD}$ Candidate in Industrial Marketing, Industrial Marketing and e-Commerce Research Group at Luleå University of Technology in Sweden.

Quang Thong Bui is also a PhD candidate in e-Commerce in the Industrial Marketing and e-Commerce Research Group at Luleå University of Technology in Sweden.
Private label competition 